\title{
Demography of Lung Cancer Patients: A Retrospective Study in Military Hospital, Dhaka
}

\author{
Elahi MQE ${ }^{1}$, Razzak $\mathrm{MA}^{2}$, Islam $\mathrm{MA}^{3}$, Alam $\mathrm{MA}^{4}$
}

https://doi.org/10.3329/jafmc.v15i1.48637

\begin{abstract}
Introduction: The habit of smoking bidis and cigarettes is of long standing and widely prevalent in the southern part of Asia and largely in Bangladesh. Currently there are limited data on the lung cancer patients of Bangladesh.
\end{abstract}

Objectives: To determine the correlation of smoking and lung cancer patients of $\mathrm{CMH}$, Dhaka and to review their demographic profile.

Materials and Methods: This retrospective hospital based study was conducted at Cancer Center, CMH, Dhaka. A total of 128 patients of lung cancer were enrolled those who were admitted to CMH Dhaka from January 2011 to December 2014. Data were collected in a predesigned format from old documents.

Results: Age range of 128 lung cancer patients were from 28 to 80 years. Most of the patients $114(89.06 \%)$ belonged to $>50$ years age group, male 105(82.03\%), 106(82.8\%) smoker, 14(10.94\%) were non-smoker and in $8(6.25 \%)$ cases the smoking habit was not mentioned in documents. Most of the patients 60(47.24\%) were from Dhaka district and belonged to lower middle class background $110(85.93 \%)$. Common coexisting diseases were COPD 30(23.43\%), HTN 32(25\%) and DM 25(19.53\%). Maximum lung cancer cases were squamous cell subtype 38(29.69\%) and adenocarcinoma $35(27.43 \%)$. TNM stage group IIIA were 25(19.53\%), IIIB $40(31.25 \%)$ and IV were 35(27.34\%). Large majority of patients were treated with chemotherapy alone $89(66.42 \%)$ and concurrent chemotherapy and radiotherapy $31(24.13 \%)$. Most of the patients of lung cancer $123(96 \%)$ died within 2 years of diagnosis.

Conclusion: In this study, there was a strong correlation between smoking and lung cancer. Majority were diagnosed late in advanced stage and treated with chemotherapy alone or chemotherapy and radiotherapy combined. Prognosis was poor in this series and $96 \%$ died within 2 years of diagnosis.

\section{Key-words: Lung cancer, Smoking, Demography}

\section{Introduction}

According to the report of World Health Organization (WHO) in 2003, worldwide, around 22 million people were living with cancer and approximately 10 million are added every year, and more than 6 million annual death ${ }^{1}$. Total burden of cancer is highest in affluent society mainly due to high incidence of tumors associated with western lifestyle. In the United States ${ }^{2}$, there were an estimated 1.3 million invasive cancer cases, of which 556,000 were death, during 2003. It is the leading cause of death among women aged 40 to 79 years and among men aged 60 to 79 years ${ }^{3}$. Lung $(17.8 \%)$, stomach $(10.4 \%)$, and liver $(8.8 \%)$ were the top three cancers contributing to the highest proportions of $12 \%$ to $13 \%$ annual cancer deaths $s^{4-6}$. In developing countries, occurance of cancers is a substantial issue. Diet- and lifestyle-related issues contribute more for the socially disadvantaged population in developing cancers like, lung, stomach, breast, cervix etc. A study in 2008 revealed that $56 \%$ of the estimated 12.7 million new cancer cases, and $63 \%$ out of 7.6 million cancer deaths occur in the less developed countries ${ }^{7}$. According to WHO (2008), in the South East Asia Region (SEAR), an estimated 1.1 million people died of cancers in 2008. A large proportion of cancer deaths occur in the economically productive age group. Each year, an estimated 1.7 million new cancer cases occur in the SEAR and the most common sites of cancers among males are the lung, followed by mouth and oropharynx (15\%), and liver (7.5\%) and among women, cervical and breast cancers are the most common, accounting for $35 \%$ of all cancer deaths ${ }^{8}$. The majority of cancer cases present at an advanced stage of the disease and with complications, which imposes a heavy burden on the family and the health-care system. It appears that the time may now be ripe to investigate about lung cancer patients in Bangladesh.

There is a lot of information on the epidemiology of lung cancer, mostly from Western countries, where the problem has assumed threatening proportions in the last few decades. Evidence from different sources has shown that smoking habits in general and cigarette smoking in particular are primarily responsible for this epidemic of lung cancer. In South Asian countries like Bangladesh, cancers of the upper alimentary tract, viz., oral, pharyngeal and oesophageal cancers, have received major attention in epidemiological studies. In India Sanghvi, Rao and Khanolkar brought out the role of bidi smoking in addition to chewing of tobacco in these cancers in the year 1955. Since then several studies have been carried out subsequently but in Bangladesh there is hardly any concrete data on the prevalence of lung cancer occurrence or its relation with smoking habit, age, gender or community. To find out the demographic features of lung cancer and to determine the correlation of smoking and lung cancer this study was designed.

\section{Materials and Methods}

This retrospective hospital based study was conducted at Cancer Center, CMH Dhaka. Total 128 admitted patients of lung cancer were enrolled those who were admitted to $\mathrm{CMH}$ Dhaka from January 2011 to December 2014. Patients' medical files were

1. Brig Gen Md Quadrat E Elahi, MBBS, MCPS, FCPS, Adviser Specialist in Medicine and Medical Oncologist, CMH, Dhaka (E-mail: quadrateelahi@gmail.com) 2. Brig Gen Md. Abdur Razzak, MBBS, MCPS, FCPS, APLAR Fellow in Rheumatology, Chief Physician, CMH, Dhaka 3. Maj Gen Md Azizul Islam, MBBS, FCPS, Fellow in Medical Oncology, Consultant Physician General, Bangladesh Armed Forces 4. Maj Md Ashraful Alam, MBBS, Trainee in Medical Oncology, Cancer Center, $\mathrm{CMH}$, Dhaka. 
collected from medical records section and prior permission was obtained from ethical committee of $\mathrm{CMH}$ Dhaka. Data were collected in a predesigned format from old documents of the patients and plotted in tables and charts. The results were analyzed with the help of computer SPSS version 16.

\section{Results}

Age of the 128 lung cancer patients were ranging from 28 to 80 years. Number of lung cancer was 1 in $\leq 30$ years, 2 in $31-40$ years, 11 in 41 50 years, 40 in $51-60$ years, 50 in $61-70$ years and 24 in $71-80$ years age group. Number of male patients were 105(82.03\%) and female patients $23(17.97 \%)$. Amongst 128 cases $106(82.81 \%)$ were smoker, $14(10.94 \%)$ were non-smoker and in $8(6.25 \%)$ cases the smoking habit was not mentioned in documents. Vast majority of patients were from Dhaka 60(46.87\%) and Chattogram 28(21.88\%) districts. Patients from other districts were Khulna and Rajshahi 11(8.53\%) each, Rangpur 9(7.03\%), Mymensingh 7(5.46\%) and Barishal $2(1.56 \%)$. Regarding socio-economic status $110(85.93 \%)$ came from lower middle class, $13(10.15 \%)$ from middle class and $5(3.9 \%)$ from upper middle class economic background. Major coexisting diseases in lung cancer patients were COPD 30(23.43\%), HTN 32(25\%), DM $25(19.53 \%)$ and IHD 14(10.93\%) (Table-I). Most histopathological types were squamous cell carcinoma $38(29-69 \%)$, adenocarcinoma $35(27.43 \%)$ and small cell carcinoma $13(10.16 \%)$. Most of the lung cancer was diagnosed in advanced stages e.g. TNM stage group IIIA 25(19.53\%), IIIB 40(31.25\%) and IV 35(27.34\%) (Table-II). Regarding treatment modalities $89(66.42 \%)$ received chemotherapy only and $31(24.13 \%)$ received concurrent chemotherapy and radiotherapy. Outcome was poor due to late presentation and 123(96\%) patients died within 2 years of diagnosis (Table-III).

Table-l: Demographic characteristics of lung cancer patients $(\mathrm{n}=128)$

\begin{tabular}{|c|c|c|c|}
\hline Characteristics & & Frequency & Percentage \\
\hline \multirow{6}{*}{ Age group (years) } & $\leq 30$ & 1 & 0.78 \\
\hline & $31-40$ & 2 & 1.56 \\
\hline & $41-50$ & 11 & 8.59 \\
\hline & $51-60$ & 40 & 31.25 \\
\hline & $61-70$ & 50 & 39.06 \\
\hline & $71-80$ & 24 & 18.75 \\
\hline \multirow{2}{*}{ Sex } & Male & 105 & 82.0 \\
\hline & Female & 23 & 18.0 \\
\hline \multirow{7}{*}{ Regional distribution } & Dhaka & 60 & 47.87 \\
\hline & Chattogram & 28 & 21.88 \\
\hline & Khulna & 11 & 8.59 \\
\hline & Rajshahi & 11 & 8.59 \\
\hline & Rangpur & 9 & 7.03 \\
\hline & Mymensingh & 7 & 5.47 \\
\hline & \begin{tabular}{|l|} 
Barishal \\
\end{tabular} & 2 & 1.56 \\
\hline \multirow{3}{*}{ Economic status } & Lower Middle & 110 & 85.93 \\
\hline & Middle & 13 & 10.15 \\
\hline & Upper Middle & 5 & 3.91 \\
\hline \multirow{3}{*}{ Smoking habit } & Smoker & 106 & 82.8 \\
\hline & \begin{tabular}{|l|} 
Non-smoker \\
\end{tabular} & 14 & 10.9 \\
\hline & Not-known & 8 & 6.3 \\
\hline \multirow{7}{*}{ Co-existing disease } & COPD & 30 & 23.43 \\
\hline & HTN & 32 & 25 \\
\hline & DM & 25 & 19.53 \\
\hline & $\mathrm{IHD}$ & 14 & 10.93 \\
\hline & Asthma & 8 & 6.25 \\
\hline & Others & 12 & 9.37 \\
\hline & \begin{tabular}{|l|} 
None \\
\end{tabular} & 7 & 5.47 \\
\hline
\end{tabular}

Table-II: Distribution of patients by types of lung cancer TNM stages $(n=128)$

\begin{tabular}{|l|l|c|c|}
\hline \multicolumn{2}{|c|}{ Characteristics } & Frequency & Percentage \\
\hline \multirow{4}{*}{ Type of cancer } & Squamous Cell & 38 & 29.69 \\
\cline { 2 - 4 } & Adenocarcinoma & 35 & 27.43 \\
\cline { 2 - 4 } & Small Cell & 13 & 10.16 \\
\cline { 2 - 4 } & Large Cell & 10 & 7.81 \\
\cline { 2 - 4 } & Metastatic Adenicarcinoma & 4 & 3.13 \\
\cline { 2 - 4 } & Others & 28 & 21.88 \\
\hline \multirow{5}{*}{ TNM Stage } & IA & 0 & 0 \\
\cline { 2 - 4 } & IB & 0 & 0 \\
\cline { 2 - 4 } & IIA & 2 & 6.25 \\
\cline { 2 - 4 } & IIB & 25 & 15.63 \\
\cline { 2 - 4 } & IIIA & 40 & 19.53 \\
\cline { 2 - 4 } & IIIB & 35 & 27.25 \\
\cline { 2 - 4 } & IV & & \\
\hline
\end{tabular}

Table -III: Distribution of lung cancer patients by treatment modalities and survival $(n=128)$

\begin{tabular}{|l|l|c|c|}
\hline \multicolumn{2}{|l|}{ Characteristics } & Frequency & Percentage \\
\hline \multirow{4}{*}{$\begin{array}{l}\text { Treatment } \\
\text { Received }\end{array}$} & Chemotherapy & 89 & 66.42 \\
\cline { 2 - 4 } & Chemotherapy+Radiotherapy & 31 & 24.13 \\
\cline { 2 - 4 } & $\begin{array}{l}\text { Operation + Chemotherapy + } \\
\text { Followed by radiotherapy }\end{array}$ & 6 & 4.48 \\
\cline { 2 - 4 } & Operation + Chemotherapy & 3 & 2.24 \\
\cline { 2 - 4 } & Radiotherapy & 4 & 2.98 \\
\cline { 2 - 4 } & Operation & 1 & 0.75 \\
\hline \multirow{4}{*}{ Survival } & $<2 \mathrm{yr}$ & 123 & 96 \\
\cline { 2 - 4 } & $2-5 \mathrm{yr}$ & 1 & 3 \\
\cline { 2 - 4 } & $>5 \mathrm{yr}$ & 1 \\
\hline
\end{tabular}

\section{Discussion}

The habit of smoking bidis and cigarettes is of long standing and widely prevalent in the southern part of Asia and largely in Bangladesh. According to a report of WHO, every year 2.5 lakh Bangladeshis die due to tobacco and the rate of death is 28 per hour 9 . In this study, among 128 lung cancer patients, 106 patients were found to be smoker which makes almost $82.81 \%$ of the study population indicating that smoking indeed can be considered as the prime factor behind lung cancer. Since smoking is still the primary risk factor for lung cancer and underscores the need for greater efforts to reduce smoking prevalence in the general population. Tobacco control programs should be pursued vigorously since these have been associated with a decline in smoking rates and subsequent lung cancer incidence rates ${ }^{10-11}$. Renewed cessation and prevention efforts should be expanded and intensified to curb prevalence of cigarette smoking and to reduce lung cancer rates eventually ${ }^{12}$. However, a significant percentage or nearly a quarter was not related to smoking. The reasons for the development of lung cancer in this segment should be further studied.

According to the results found in this study lung cancer is most common in male smokers of $>50$ years. It is also found in some other studies that lung cancer is predominant in elderly patients ${ }^{12}$. The study also showed that lung cancer increases with age but is uncommon in persons less than 40 years and males outnumber females in all age groups. It is found that maximum number of 
patients in our series is from Dhaka District. The reason is that $\mathrm{CMH}$ Dhaka is located in Dhaka district where communication facility is good which makes it convenient to report sick. Population is huge, air population is more and more number of uniformed and civilians employees are posted in and around Dhaka Cantonment. Smoking habit might be more amongst them. This is consistent with recent international trends which still show that lung cancers are more common in men although rates in females had been rising, and differences in sexes had been narrowing ${ }^{12}$.

Among the cases of diagnosed lung cancer patients, it was seen that the number of adenocarcinoma patients were closer to the number of squamous cell carcinoma patients and it is very hard to determine any correlation between the type of lung cancer and their etiology. According to other studies the emerging predominance of adenocarcinoma and squamous cell carcinoma in lung cancer rates have been attributed to changes in smoking habits and changes in the type of tobacco in cigarettes ${ }^{13}$. With the switch from non-filtered to filtered cigarettes, the depth of inhalation is altered because with unfiltered cigarettes, inhalation tend to be shallow with chemical carcinogen deposition centrally in bronchial area, giving rise to SCLC while smoke from filtered milder cigarettes may be more deeply inhaled, resulting in more peripheral deposition and giving rise to adenocarcinoma ${ }^{14}$. The reduction in nicotine content also promote deeper inhalation as smokers tend to compensate and changes in cigarette composition reduced the yield of carcinogenic polycyclic aromatic hydrocarbons (PAH), inducers of squamous cell carcinoma, while increasing the yield of carcinogenic tobacco-specific $\mathrm{N}$-nitrosamines (TSNAs), inducers of adenocarcinoma ${ }^{15,16}$.

Most lung cancer patients had coexisting diseases and only $7 \%$ had no appreciable disease. Co-existence of cancer and these diseases often causes a delay in the diagnosis. Patients with cancer are vulnerable to develop active pulmonary diseases because of immunosuppression due to malnutrition, or due to the use of intensive treatment modalities, such as aggressive chemotherapy. Since there is no concrete single treatment for cancer patients but mixture of treatment protocol it is hard and much complicated process to analyze and relate which patient will response better to which treatment. Not many lung cancer patients were seen and diagnosed at the hospital at an early stage of the disease and hence effective procedures to improve survival was not feasible to perform. Instead basic supportive care or palliative care was the main management strategy for these patients. Late diagnosis contributed greatly to the observed mortality rate. This is not much different in other studies, wherein more than $85 \%$ of cases present with locally advanced or metastatic disease. Since most of the patients were diagnosed in the later stages very few patients survived more than 2 years. Though the study provides an overview of the distribution of patients in respect to types of lung cancer, coexisting diseases, required treatment protocols and survival rates; more detailed scientific studies must be performed to find the etiological correlation, exact demographic profile and relevant co morbidity.

\section{Conclusion}

An increased trend of cancer is found in the people of Bangladesh and lung cancer is the leading cancer among the Bangladeshi male. Undoubtedly smoking is one of major reason behind it but other demographic or environmental factors cannot be overruled as well. Moreover it was also seen that lower middle class people are more susceptible to the smoking habit as well as to the harmful environment with toxic gas which may make them prone to lung cancer. Therefore it can be concluded that demographic factors like age, sex, lifestyle, diet, habits, and community can be significant factors in lung cancer prevalence but further detailed study with larger study population throughout the country is suggested.

\section{References}

1. Stewart BW, Kleihues P, editors. World Cancer Report. Lyon: IARC Press; 2003.

2. Schottenfeld D, Beebe-Dimmer JL. Advances in cancer epidemiology: Understanding causal mechanisms and the evidence for implementing interventions. Annu Rev Public Health, 2005; 26:37-60.

3. Jemal A, Murray T, Samuels A et al. Cancer statistics, 2003. CA Cancer $\mathrm{J}$ Clin 2003; 53:5-26.

4. Ferlay J et al, editor. Globocan 2000. Cancer Incidence, Mortality 38 Annals of Cancer Research and Therapy Vol. 20, No. 1, 2012 and Prevalence Worldwide. Lyon, France: IARC Cancer Base No. 5; 2001.

5. Jan S, Kimman M, Kingston D et al. The Socioeconomic Burden of Cancer in Member Countries of the Association of Southeast Asian Nations (ASEAN) - Stakeholder Meeting Report. Asian Pac J Cancer Prev 2012; 13:407-9.

6. Parkin DM. Global cancer statistics in the year 2000. Lancet Oncol 2001; 2:533-43.

7. Pisani P, Bray F, Parkin DM. Estimates of the world-wide prevalence of cancer for 25 sites in the adult population. Int J Cancer, 2002; 97:72-81.

8. WHO. Cancer in the South-East Asia Region (SEA) Region - Quick facts. 2008 [cited 01 June 2012]; Available from: http://www.searo. who. int/en/section1174/section1459_16435.htm.

9. Torre LA, Bray F, Siegel RL et al. Global cancer statistics, 2012. CA Cancer J Clin. 2015 Mar; 65(2):87-108. doi: 10.3322/caac.21262. Epub 2015 Feb 4

10. Barmoya J, Glantz S. Association of the California tobacco control program with declines in lung cancer incidence. Cancer Causes Control 2004; 15: 689-695.

11. Polednak AP. Lung cancer incidence trens in black and white young adults by gender (United States). Cancer Causes Control 2004; 15: 665-670.

12. Devesa SS, Bray F, Vizcaino AP et al. International lung cancer trends by histologic type male:female differences diminishing and adenocarcinoma rates rising. Int J Cancer 2005; 117:294-99.

13. Hoffman D, Djordjevic MV, Hoffman I. The changing cigarette. Prev Med 1997; 26:427-34.

14. Wynder EL, Hoffman D. Re: Cigarette smoking and histopathology of lung cancer. J Natl Cancer Inst 1998; 90:1486-8.

15. Djordjevic MV, Hoffman D, Hoffman I. Nicotine regulates smoking patterns. Prev Med 1997; 26: 435-440.

16. Morgensztern D, Ng SH, Gao SF, et al. Trends in stage distribution for patients with non-small cell lung cancer: A National Cancer Database survey. J Thorac Oncol 2010; 5:29-33. 